\title{
Admissibilidade da prova pericial najurisprudência norte-americana: o que podemos aprender com os casos Frye, Daubert e Kumho
}

\author{
Admissibility of expert witness in north american jurisprudence: what we can learn from \\ Frye, Daubert and Kumho cases
}

Murilo Teixeira Avelino'

${ }^{1}$ Universidade Federal da Bahia - UFBA, Brasil

\section{Resumo}

\begin{abstract}
A prova pericial se apresenta como um dos desafios da prática judicial. Especialmente para as demandas complexas, sua produção pode ser dispendiosa em termos econômicos e temporais. Por isso, o exame de sua admissibilidade deve ser criterioso. O código de processo civil brasileiro não se ocupa cuidadosamente de critérios de admissibilidade da prova técnica e científica, cabendo ao jurista conformar o conteúdo do que se entende por prova necessária e útil. O estudo da jurisprudência norte-americana surge, nesse contexto, como um instrumento útil de identificação de requisitos de admissibilidade que podem ser aplicados Direito brasileiros. Este artigo se debruça sobre três casos paradigmáticos - Freye, Daubert e Kumho - buscando identificar o que podemos aprender
\end{abstract} com eles.

Palavras-chave: prova. perícia. admissibilidade.

\begin{abstract}
Expert witness evidence presents itself as one of the challenges of judicial practice. Especially for complex demands, its production can be costly in economic and temporal terms. Therefore, the examination of its admissibility must be careful. The Brazilian civil procedure code does not carefully deal with the criteria for the admissibility of technical and scientific evidence, and it is up to the jurist to conform the content of what is meant by necessary and useful evidence. The study of North American jurisprudence emerges, in this context, as a useful instrument for identifying admissibility requirements that can be applied in Brazilian law. This article watches over three paradigmatic cases - Freye, Daubert and Kumho - seeking to identify what we can learn from them.
\end{abstract}

Keywords: evidence. expert witness. admissibility.

\section{Introdução}

A perícia representa um enorme desafio na prática judicial. Trata-se de meio de prova cuja produção, especialmente diante da complexidade das demandas coletivas e estruturais, é cara e normalmente morosa. À sua produção se impõem dificuldades não só de ordem jurídica, mas de ordem econômica e social, além daquelas decorrentes, naturalmente, da própria natureza do conhecimento técnico e científico a ser aplicado.

O ponto que se deve ter em mente para admitir a produção da prova técnica ou científica no processo é a sua necessidade. Fatos incontroversos, notórios e admitidos dispensam a produção de prova. Da mesma forma, fatos sobre os quais recai presunção, exceto se questionados forem. Também não se deve admitir 
a prova inútil, ou seja, aquela que objetiva provar alegação de fato incapaz de influenciar na decisão da causa, ou seja, fatos impertinentes. Especialmente quanto à prova pericial, em virtude mesmo de sua natureza, não deve ser admitida quando a alegação de fato objeto da prova independe de conhecimentos especializados para ser acertadal. A inadmissibilidade da perícia face à sua desnecessidade, desde que fundamentada, não afronta qualquer elemento do direito fundamental à prova2.

\section{Necessidade como critério de admissibilidade da prova pericial}

O critério de necessidade é eminentemente um elemento jurídico relacionado à eficiência, efetividade, adequação e à razoável duração do processo. Não se pode esquecer, ainda, que o direito à prova, de índole constitucional fundamental, abrange o direito a requerer e ver admitida a produção da prova. Assim, é a partir destes parâmetros, de ordem constitucional, que deve ser analisada a admissibilidade da perícia. O Juiz não pode, sob pena de extrapolar as suas funções no processo, admitir ou inadmitir arbitrariamente a produção de prova técnica ou científica ${ }^{3}$.

Este é um momento nevrálgico, onde se põem em contraste o direito fundamental à prova e o direito fundamental a um processo com duração razoável. Pondera Moacyr Amaral Santos, citando Carnelutti, em lição indispensável por sua precisão:

Carnelutti, sobre o assunto, como em tudo que se refere a processo, pondera com exímia sabedoria: "Êste é, talvez, o lado mais delicado do incidente de admissão das provas, porque aí estão, em contraste, ainda uma vez, as duas exigências de justiça e economia, isto é, em última análise, a de fazer bem e a de fazer depressa. Incidiria em êrro, certamente, quem, tendo em consideração sòmente a primeira, deduzir daí que, por isso e quod abundant non vitiat, as provas devam ser admitidas sem qualquer resguardo de economia: antes muito que muito pouco. É preciso, entretanto, olhar para o reverso da medalha; a justiça que chega tarde é geralmente uma justiça vã; e não há instituto que mais influa no seu protelamento que o da produção das provas.”"

É preciso trazer esta lição para os dias atuais, pois a fundamentação quanto à necessidade ou não da perícia deverá conter robusta fundamentação.

Em linhas gerais, possível delimitar que eficiência e efetividade não se confundem. Em direito, quando se trata da efetividade, referimo-nos ao cumprimento das normas jurídicas. Quando a norma produz os efeitos para as quais foi posta no ordenamento, está é considerada efetiva. Já a eficiência leva em conta a relação entre os meios empregados e os resultados alcançados em vista a finalidades preestabelecidas. Ao lado da dimensão de administração gerencial, aplicável diretamente ao Poder Judiciário (art. 37, caput, CR), surge com o CPC uma perspectiva diferente para a aplicação da eficiência no processo, qual seja, sua relação com a gestão do processo. Daí se pode falar em duas perspectivas diversas da eficiência no sistema processual. A primeira delas se relaciona com a velocidade do procedimento e a redução dos custos; a segunda com a qualidade da prestação da atividade jurisdicional. Poder-se-ia falar, então, em eficiência quantitativa e eficiência qualitativa.

A primeira se confunde com o princípio da razoável duração do processo e com o princípio da economia processual. O princípio da eficiência, então, identifica-se com a sua vertente qualitativa, informando a prestação da jurisdição de forma mais completa, evitando o acumulo e repetição de demandas judiciais.

1 MIRANDA, Pontes de. Comentários ao Código de Processo Civil-tomo IV. Rio de Janeiro: Forense, 1974. p. 447. Segundo o autor: "Se a perícia seria de prova de fato, ou ato, cujo conhecimento para conclusão não dependesse de técnica, a superfluidade afasta a permissão e o juiz tem de indeferir o pedido."

2 Veja-se, nesse sentido, o entendimento do STJ: DIREITO PROCESSUAL CIVIL. INDEFERIMENTO DE PERÍCIA REQUERIDA PELA PARTE. O magistrado pode negar a realização de perícia requerida pela parte sem que isso importe, necessariamente, cerceamento de defesa. De fato, o magistrado não está obrigado a realizar todas as perícias requeridas pelas partes. Ao revés, dentro do livre convencimento motivado, pode dispensar exames que repute desnecessários ou protelatórios. Precedente citado: AgRg no AREsp 336.893-SC, Primeira Turma, DJe 25/9/2013. (REsp 1.352.497-DF, Rel. Min. Og Fernandes, julgado em 4/2/2014).

3 MIRANDA, Pontes de. Comentários... - tomo IV. Ob. cit. p. 445.

4 SANTOS, Moacyr Amaral. Prova Judiciária no Cível e Comercial - vol. 1. São Paulo: Max Limonad, 1954. p. 256. 
No que tange à efetividade, esta não se relaciona necessariamente com o tempo de duração do processo, mas sim com a aptidão das normas para transplantarem seu conteúdo normativo em fato, ou seja, seu potencial de concretização. A relação entre eficiência e efetividade é posta por Leonardo Cunha:

É possível que um processo seja efetivo sem ser eficiente, atingindo-se ao resultado pretendido, mas de forma insatisfatória, demorada ou inadequada. O processo, por sua vez, será eficiente se atingir o resultado pretendido de modo satisfatório. É possível, então, que o processo seja efetivo, sem ser eficiente, mas se for eficiente, será necessariamente efetivo. ${ }^{5}$

Há uma relação íntima com a admissibilidade da prova técnica e científica. Na medida em que o seu procedimento de produção impõe necessariamente uma dilação do tempo do processo, o aumento de custos e a problematização a respeito de conhecimentos que exigem a participação de um terceiro responsável por traduzi-los ao homem médio, o critério de necessidade deve passar necessariamente por um juízo de efetividade e eficiência.

Perceba-se: se a prova da alegação de fato não depender de aplicação de conhecimentos especializados, ou a sua verificação for impossível em face à própria limitação de tais conhecimentos, ou ainda, já estando o fato incontroverso (por admissão da parte ou face a outras provas produzidas ${ }^{6}$ ), esta dilação tornará o procedimento ineficiente e inefetivo, devendo-se inadmitir a perícia ${ }^{7}$. Isto porque haverá a realização de atos que não servirão à solução final do caso. "Provados, de alguma maneira, nos autos, os fatos que seriam objeto da perícia requerida, esta deve ser indeferida pelo juiz, como diligência inútil”.

Atos de instrução desnecessários, dispensáveis, inaptos a alterar a solução da causa ou influenciar o convencimento vão de encontro às relações menores custos (temporais, financeiros, sociais) - melhores resultados (da mesma forma temporais, financeiros, sociais) inerentes à ideia de eficiência.

Ainda, a prestação da atividade jurisdicional há de ser adequada. Só há processo devido se for adequado. O princípio da adequação é extraído do próprio devido processo legal. O princípio da adequação informa um procedimento destinado à plena efetividade da tutela do direito material. É que o processo deve ser instrumento capaz de promover a realização do direito material, levando-se em conta a sua natureza para a conformação da técnica processual ideal. Tanto legislador quanto decididor são destinatários do princípio da adequação. O legislador deve editar as regras de processo tendo em vista o direito material ao qual o processo servirá, sempre tendo em conta a necessidade de prestar a tutela processual com efetividade. Nesta medida, ao prever as hipóteses de aplicação de conhecimentos especializados no processo, o legislador o fez para admitir a aquisição destes instrumentos como forma de solucionar os conflitos.

Da mesma forma, cabe ao juiz uma análise de adequação para perceber se o caso concreto exige ou não a utilização de técnica prevista abstratamente. Ou seja, no que refere à produção da prova, exige-se do

5 CUNHA, Leonardo Carneiro da. A previsão do princípio da eficiência no projeto do novo código de processo civil brasileiro. Repro, São Paulo: RT, v. 233, 2014. p. 77.

6 Marinoni e Arenhart afirmam que “estando o fato já devidamente provado, não há por que deferir a produção da prova pericial (art. 464, $1^{\circ}$, II, CPC/2015). Entretanto, se a afirmação de fato ainda puder ser demonstrada no sentido contrário, a parte interessada poderá requerer - e logicamente ver deferida - a prova pericial”. MARINONI, Luiz Guilherme; ARENHART, Sérgio Cruz. Prova e Convicção. São Paulo: RT, 2015. p. 854. Perceba-se, então, que esta hipótese não trata de fato incontroverso em face a outras provas produzidas. Se o juiz admite a produção da prova pericial sob o argumento de que se pode convencer do contrário, é porque necessariamente as alegações do sujeito que requereu a perícia desconstituíram a própria certeza que ele antes possuía. Assim, não há mais falar em fato já devidamente provado. Por isso, esta hipótese trazida pelos autores não procede. Pois se há dúvida, não há fato já provado apto a justificar a inadmissibilidade da perícia. A prova que justifica a inadmissibilidade da prova pericial é aquela que retira do juiz qualquer elemento de dúvida quanto à alegação de fato. Como afirma Moacyr Amaral Santos, "a rejeição de provas sòmente deverá verificar-se, quando legalmente admissíveis, em hipóteses tão meridianamente claras que não possa surgir dúvida alguma sôbre a desnecessidade da prova considerada supérflua.” ANTOS, Moacyr Amaral, Prova Judiciária... - vol. 1. Ob. cit. p. 256.

7 "[A prova pericial] Será indeferida, contudo, se for desnecessária em vista de outras provas produzidas nos autos ou quando a verificação do fato for impraticável” MARINONI, Luiz Guilherme; MITIDIERO, Daniel. Código de processo civil comentado artigo por artigo - $2^{a}$ ed. São Paulo: RT, 2010. pp. 400-401.

8 CINTRA, Antonio Carlos de Araujo. Comentários ao Código de Processo Civil - vol. IV. Rio de Janeiro: Forense, 2000. p. 205. 
magistrado um juízo a respeito da adequação daquela técnica para provar. O princípio da adequação será respeitado se o juízo de admissibilidade da prova técnica ou científica ultrapassar o questionamento a respeito de se esta prova é adequada, apta, à comprovação.

É o exemplo do julgamento do Recurso Especial Repetitivo n 1485832/MG, onde se decidiu pela desnecessidade de perícia em todos os bens apreendidos para a verificação de violação de direitos autorais. É o caso das operações para apreensão de bens falsificados, onde a grande quantidade de produtos (CDs, DVDs, entre outros) torna desnecessária a perícia em cada um daqueles objetos e a identificação de cada um dos titulares de direitos violados. O STJ entendeu adequada e eficiente a perícia por amostragem. Outra solução não poderia ter sido tomada. Caso se entendesse pela necessidade de perícia em cada um dos bens apreendidos, haveria patente ferimento à razoável duração do processo ${ }^{9}$.

A partir daí, é possível identificar duas ligações umbilicais dos princípios supracitados com o juízo de admissibilidade da prova: a primeira diz respeito à relação com o devido processo legal, servindo como mais um instrumento à sua concretização, dele derivando e com ele sendo aplicado ${ }^{10}$; a segunda se refere a sua função de ponte entre o processo e o direito material em análise. O procedimento deve atender à finalidade e natureza do direito tutelado, como afirma Leonardo Cunha:

É preciso, enfim, haver uma adequação do processo às particularidades do caso concreto. Para que a tutela jurisdicional seja efetiva, concretizada pela exigência de um devido processo legal, é preciso que haja adequação. O princípio da adequação é extraído, então, da garantia de inafastabilidade do controle jurisdicional e, igualmente, da cláusula do devido processo legal. ${ }^{11}$

Informado por tais normas fundamentais do processo, o juízo prévio quanto à admissibilidade da prova técnica e científica exige resposta a duas perguntas: a) a prova é relevante à comprovação da alegação de fato? Se sim, b) há alguma maneira menos dilatória e dispendiosa que sirva à prova? Se não, admite-se a produção da prova pericial, pois necessária à solução do caso.

Quanto à mencionada relevância, a doutrina norte-americana ajuda a compreendê-la. É que a produção deste meio de prova só deve ser admitida quando servir a provar uma alegação de fato referente a determinada questão debatida no processo. Conforme atenta Yeazell, "For a piece of information to be relevant to a legal propositions means that the informations tends to prove or disprove something the governing substantive law says matters" ${ }^{12}$. Ou seja, se a prova é irrelevante, ela não serve à comprovação de qualquer

9 RECURSO ESPECIAL. PROCESSAMENTO SOB O RITO DO ART. 543-C DO CÓDIGO DE PROCESSO CIVIL. RECURSO REPRESENTATIVO DA CONTROVÉRSIA. VIOLAÇÃO DE DIREITO AUTORAL. PERÍCIA SOBRE TODOS OS BENS APREENDIDOS. DESNECESSIDADE. ANÁLISE DOS ASPECTOS EXTERNOS DO MATERIAL APREENDIDO. SUFICIÊNCIA. IDENTIFICAÇÃO DOS TITULARES DOS DIREITOS AUTORAIS VIOLADOS. PRESCINDIBILIDADE. RECURSO PROVIDO. 1. Recurso Especial processado sob o regime previsto no art. 543-C, § $2^{\circ}$, do CPC, c/c o art. $3^{-}$do CPP, e na Resolução n. 8/2008 do STJ. TESE: É suficiente, para a comprovação da materialidade do delito previsto no art. 184, $§ 2^{\circ}$, do Código Penal, a perícia realizada, por amostragem, sobre os aspectos externos do material apreendido, sendo desnecessária a identificação dos titulares dos direitos autorais violados ou de quem os represente. 2. Não se exige, para a configuração do delito previsto no art. 184, § 2º do Código Penal, que todos os bens sejam periciados, mesmo porque, para a caracterização do mencionado crime, basta a apreensão de um único objeto. 3. A constatação pericial sobre os aspectos externos dos objetos apreendidos já é suficiente para revelar que o produto é falso. 4 . A violação de direito autoral extrapola a individualidade do titular do direito, pois reduz a oferta de empregos formais, causa prejuízo aos consumidores e aos proprietários legítimos, fortalece o poder paralelo e a prática de atividades criminosas, de modo que não é necessária, para a caracterização do delito em questão, a identificação do detentor do direito autoral violado, bastando que seja comprovada a falsificação do material apreendido. 5. Recurso especial representativo da controvérsia provido para reconhecer a apontada violação legal e, consequentemente, cassar o acórdão recorrido, reconhecer a materialidade do crime previsto no art. 184, $\$ 2^{\circ}$, do Código Penal e determinar que o Juiz de primeiro grau prossiga no julgamento do feito (Processo n. 0024.12.029829-4). (STJ, Resp. 1485832/MG, Terceira Seção, Relator Ministro Rogério Schietti Cruz, DJ 21/08/2015). Grifamos.

10 "Pelo princípio constitucional do direito de ação, além do direito ao processo justo, todos têm o direito de obter do Poder Judiciário a tutela jurisdicional adequada. Não é suficiente o direito à tutela jurisdicional. É preciso que essa tutela seja a adequada, sem o que estaria vazio de sentido o princípio". NERY JUNIOR, Nelson. Princípios do Processo na Constituição Federal. São Paulo: RT, 2013. p. 187.

11 CUNHA, Leonardo. A Atendibilidade dos Fatos Supervenientes no Processo Civil. Coimbra: Almedina, 2012. p. 83.

12 YEAZELL, Stephen C. Civil Procedure. New York, NY: Aspen Publishers, 2008. p. 416. 
questão a ser decidida. Para Manzano, "quando se fala em relevância da prova em geral, pensa-se em sua aptidão para demonstrar um fato que tem importância para o julgamento da causa” ${ }^{13}$. A prova relevante é aquela apta a influenciar o resultado do julgamento.

Conforme aponta Taruffo, a análise de relevância da prova não perpassa um exame do grau de relevância. Em verdade, é noção excludente: ou a prova serve para a apuração de um fato, ou não deve ser admitida ${ }^{14}$. Na própria ideia está inscrita a perspectiva de economicidade jurídica (dilação indevida) ou econômica (dispêndio financeiro/limitação do poder econômico dos sujeitos), conquanto pensemos melhor didaticamente separarmos estes juízos. A razão é simples: pode haver mais de um meio de prova útil à verificação das alegações de fato; daí necessário examinar qual o mais econômico.

A perícia tem um objeto específico e inconfundível: aportar ao processo elementos de fato que somente o conhecimento especializado é capaz de trazer. O objeto desta prova não é residual, mas específico. A análise de sua necessidade é que deve ser criteriosa, devendo o magistrado confronta-la face a outros meios de prova.

É exatamente na identificação dos critérios que tornam a prova pericial necessária e relevante que o presente trabalho pretende contribuir, com os olhos voltados à produção jurisprudencial norteamericana, especialmente em três casos paradigmáticos: Frye, Daubert e Kumho.

\section{Notas sobre o sistema norte-americano}

Os sistemas de common law e civil law afastam-se no que refere ao momento de verificação da técnica ou ciência a ser aplicada no processo. É comum que as nossas lições se debrucem com o problema do conhecimento especializado na fase de valoração da prova, momento em que o magistrado se depara já com a prova produzida. Por outro lado, o processo norte-americano demonstra esta preocupação na fase de admissibilidade da evidence. Nos casos tratados adiante, a análise da credibilidade do conhecimento especializado ocorre no momento de admissão da prova. É como bem aponta Michele Taruffo:

Enquanto na perspectiva do caso Daubert o problema foi abordado em termos de admissibilidade das provas periciais, uma vez que no sistema americano o problema é fundamentalmente da seleção das provas que poderão ou não ser apresentadas, nos outros sistemas processuais a questão da prova científica possui ainda outro aspecto: como foi mencionado, um dos problemas mais relevantes que permeiam as provas periciais é a valoração, por parte do juiz, dos resultados do trabalho do perito. Em verdade, nos sistemas de civil law, esse é o verdadeiro momento em que a validade científica das provas técnicas é avaliada pelo juiz. ${ }^{15}$

A conformação do sistema processual norte-americano diverge da que conhecemos em nosso Direito, especialmente no que tange à produção e controle da prova. Interessa-nos aqui, especialmente por sua peculiaridade se comparada ao nosso sistema, a fase prévia ao julgamento, o pretrial. Trata-se de uma fase de preparação do processo para julgamento, admitindo-se a produção das provas e resolvendose eventuais questões incidentais. Tem por função exatamente instruir a causa e fazer com que as partes se confrontem com as provas e os argumentos que serão apresentados na fase de trial pela parte adversa, momento em que as questões controvertidas são fixadas com segurança. A chamada disclosure, procedimento de abertura das próprias provas ao adversário, deve ser regida pela boa-fé, sendo possível

13 MANZANO, Luíz Fernando de Moraes. Prova Pericial: Admissibilidade e assunção da prova científica e técnica no processo brasileiro. São Paulo: Atlas, 2011. p. 188. Interessante, quando ao tema, o raciocínio de Nathália Gonçalves de Macedo Carvalho: "Essa parece ser uma importante contribuição a ser extraída do direito norte-americano. O Novo Código de Processo Civil manteve a possibilidade de indeferimento das provas inúteis e protelatórias, o que significa dizer, que as provas inúteis, ou seja, aquelas cujo fato que se pretenda provar não tenha relação com a lide, ou ainda, àquelas que pretende provar fato que já foi objeto de prova, não devem ser admitidas. Isso, de certa forma, nada mais é do que a aferição da relevância da prova." CARVALHO, Nathália Gonçalvez de Macedo. Introdução ao federal rules of evidence e os pontos de encontro com o Código de Processo Civil 2015. JOBIM, Marco Félix; FERREIRA, William Santos (coords). Direito Probatório. Salvador: JusPodivm, 2015. p. 870 .

14 TARUFFO, Michele. Uma simples verdade. O juiz e a construção dos fatos. Madri: Marcial Pons, 2012. pp. 167-169.

15 TARUFFO, Michele. A prova. São Paulo: Marcial Pons, 2014. p. 97. 
até a imposição de sanção por contempt of court àqueles que impõem dificuldades ou tentam burlar as exigências de trazer à tona as suas provas ${ }^{16}$.

Permite-se no pretrial a autocomposição, o que é favorecido pelo fato de as partes se depararem com as provas e os argumentos uma da outra (discovery). Nesta fase, frise-se, há um conhecimento amplo de todas as provas a serem produzidas pela parte contrária, sendo possível analisá-las, verificando-se antecipadamente a sua legitimidade e a importância que terão para o julgamento. Conforme atenta Yeazell, "a party to a civil lawsuit may be compelled to provide the other side with all sorts of information that wakens his claim or defense" ${ }^{17}$, incidindo nesta fase somente algumas limitações pontuais ${ }^{18}$.

Boa parte das causas se encerram por autocomposição já na fase de pretrial após a discovery.

Discovery ends lawsuits for two reasons. First, discovery produces information about the merits of the lawsuit and permits parties to make informed judgements about the strengh of their and their opponent's positions. (...) Second, because discovery costs time and money, it might enable one of the parties simply to wear the other down - or both sides to wear each other downwithout regar to the merits of the case ${ }^{19}$.

A doutrina norte-americana aponta, contudo, que apesar da ideia do discovery ser a de preparar as partes para o julgamento, evitando surpresas, muitas vezes esta fase se torna uma disputa de "gato e rato" onde se busca conhecer muito dos trunfos do adversário sem, contudo, informá-lo completamente das próprias razões. Por isso, esta fase exige grande habilidade dos advogados, consubstanciando-se numa das mais caras e demoradas fases do procedimento. ${ }^{20}$ De toda forma, cumpre às partes revelarem as suas provas.

É na fase do pretrial que há o juízo de admissibilidade da perícia.

As normas que informam a admissibilidade da expert evidence no direito norte-americano encontram como fonte normativa principal três importantes casos, além da Federal Rules of Evidence, act destinado a regular a produção das provas naquele direito.

Antes de nos debruçarmos sobre estes casos, importa notar que no processo norte-americano, quando questões relacionadas a conhecimentos especializados exigem a assistência de peritos, estes funcionam como verdadeiros colaboradores das partes, sujeitos parciais, que auxiliam na preparação do caso e no desenvolvimento da estratégia de cada um dos sujeitos do processo ${ }^{21}$. É possível falar em perito da parte, em comparação ao nosso perito do juízo.

16 PEÑA, Eduardo Chemale Selistre. Poderes e atribuições do juiz. São Paulo: Saraiva, 2014. pp. 66-67.

17 YEAZELL, Stephen C. Civil Procedure. Ob. cit. p. 29.

18 Continua Yeazzel: "Three restrictions limit the otherwise broad powers od civil discovery. See Rule 26(b)(2) and (c). First, parties may discover only evidence that is relevant to a claim or defense in the case. Second, even if relevant, the requested information may be protected if privileged. (...) Finally, even relevant, inprivileged information may be undiscoverable if a party can convince a court that is potential for 'annoyance, embarrassment, oppression, or undue burden or expense' outweight its value. Rule 26(c)”. Idem. Ib idem. p. 29.

19 Idem. Ib idem. p. 415. Em outro momento, afirma o autor: "discovery aims to put the parties in a position from wich they can realistically asses the merits.” p. 472. No mesmo sentido, aponta Eduardo Chemale Selistre Peña: “A discovery é considerada o nó vital do processo civil norte-americano. Não há vitória que não seja intimamente conectada com o desenvolvimento da descoberta dos fatos na fase preliminar. Por ocupar essa posição central no processo, a discovery é importantíssima na definição do destino de muitos deles. Inclusive, é nessa etapa que muitos terminam. As informações colhidas nesse momento possuem um valor grandioso quando se pensa na possibilidade de um acordo entre as partes." PEÑA, Eduardo Chemale Selistre. Poderes... Ob. cit. pp. 68-69.

20 SPENCER, A. Benjamin. Civil Procedure - A Contemporary Approach. St. Paul, MN: Thomson/West, 2007. p. 570.

21 Idem. Ib idem. p. 625. Segundo Taruffo, "Cria-se, assim, a figura do perito como $<<$ mercenário $>>$, a postos para servir à parte que primeiro o convocar.” TARUFFO, Michele. A Prova. Ob. cit. p. 88. Ambos os autores atentam para a Rule 706 da Federal Rules of Evidence que permite a nomeação de um perito do juízo. Esta técnica, todavia, é tão raramente utilizada que não chama atenção quando da análise daquele ordenamento. Decorre essa rara utilização do perito nomeado pelo juízo da própria natureza adversarial do sistema estadunidense. Na doutrina nacional, aponta esta característica Diogo Rezende de Almeida (ALMEIDA, Diogo de Assumpção Rezende. A prova pericial no processo civil: o controle da ciência e a escolha do perito. Rio de Janeiro: Renovar, 2011. pp. 14-15). 
Todavia, quando se manifestam em juízo, durante a fase de trial, os expertsfuncionam como testemunhas. Por isso, é necessário um rígido controle no que tange à admissibilidade da prova pericial no processo norte-americano, onde o perito é visto como uma espécie de testemunha qualificada. Não se exige dele imparcialidade e, por isso, para que seja admitido a "testemunhar" no processo, é necessário um exame acurado de diversos requisitos construídos jurisprudencialmente e também elencados na Federal Rules of Evidence. Conforme aponta Yeazell:

Expert typically testify to the inferences one can draw about causes of an event by applying their especial knowledge to the evidence available. Before a court will let an expert testify, the party presenting such testimony must establish that he or she is an expert and that the expertise is relevant to contested issues ${ }^{22}$.

Nesse sentido, na própria Federal Rules of Civil Procedure há uma série de regras relativas ao expert que tendem a verificar a sua confiabilidade. Nos termos da rule $26(a)(2)^{23}$ as partes devem identificar todos os profissionais que atuarão em seu interesse, sua qualificação e experiência como expert witness, além de impor a eles a obrigação de trazer um resumo do que pretendem apresentar no eventual julgamento, a base técnica ou científica de sua opinião e as informações que se utilizou para a construção dos seus $\arg u m e n t o s^{24}$.

A previsão de todos estes ditames visa proteger a qualidade e credibilidade das provas produzidas, protegendo-se o processo daquilo que se costuma chamar de junk science $e^{25}$, ou seja, uma pretensa ciência produzida sem critérios confiáveis, no interesse somente de uma das partes, sem preocupação criteriosa com os métodos utilizados e com os resultados obtidos. No processo estadunidense, pois, são dois os critérios que acabam por informar a admissibilidade da prova técnica e científica: relevância e confiabilidade $^{26}$. Entendemos, conforme já mencionado anteriormente, que a relevância está presente também em nosso ordenamento como um dos elementos da necessidade de produção da prova. Ademais, o critério de confiabilidade é que exige acurado exame do conhecimento especializado que será aportado no processo.

Este é o aspecto que torna problemática a produção da prova pericial. Desde o momento de sua admissibilidade, o tribunal se confronta com conhecimentos a si indisponíveis (=conhecimentos indisponíveis ao homem-médio). Por isso o reforço da necessidade de proteger o processo das junk sciences desenvolvendo os métodos de admissibilidade da produção da prova técnica e científica.

\section{YEAZELL, Stephen C. Civil Procedure. Ob. cit. p. 449.}

23 Rule 26. Duty to Disclose; General Provisions Governing Discovery. (a) Required Disclosures. (2) Disclosure of Expert Testimony. (A) In General. In addition to the disclosures required by Rule 26(a) (1), a party must disclose to the other parties the identity of any witness it may use at trial to present evidence under Federal Rule of Evidence 702, 703, or 705. (B) Witnesses Who Must Provide a Written Report. Unless otherwise stipulated or ordered by the court, this disclosure must be accompanied by a written report - prepared and signed by the witness - if the witness is one retained or specially employed to provide expert testimony in the case or one whose duties as the party's employee regularly involve giving expert testimony. The report must contain: (i) a complete statement of all opinions the witness will express and the basis and reasons for them; (ii) the facts or data considered by the witness in forming them; (iii) any exhibits that will be used to summarize or support them; (iv) the witness's qualifications, including a list of all publications authored in the previous 10 years; (v) a list of all other cases in which, during the previous 4 years, the witness testified as an expert at trial or by deposition; and (vi) a statement of the compensation to be paid for the study and testimony in the case. (C) Witnesses Who Do Not Provide a Written Report. Unless otherwise stipulated or ordered by the court, if the witness is not required to provide a written report, this disclosure must state: (i) the subject matter on which the witness is expected to present evidence under Federal Rule of Evidence 702, 703, or 705; and (ii) a summary of the facts and opinions to which the witness is expected to testify. (D) Time to Disclose Expert Testimony. A party must make these disclosures at the times and in the sequence that the court orders. Absent a stipulation or a court order, the disclosures must be made: (i) at least 90 days before the date set for trial or for the case to be ready for trial; or $\quad$ (ii) if the evidence is intended solely to contradict or rebut evidence on the same subject matter identified by another party under Rule 26(a)(2)(B) or (C), within 30 days after the other party's disclosure. (E) Supplementing the Disclosure. The parties must supplement these disclosures when required under Rule 26(e).

24 SPENCER, A. Benjamin. Civil Procedure... Ob. cit. p. 625.

25 TARUFFO, Michele. A Prova. Ob. cit. p. 95.

26 MANZANO, Luiz Fernando de Moraes. Prova Pericial... Ob. cit. p. 188. 


\section{Caso Frye vs. United States}

Merece destaque o caso Frye us. United States (mais conhecido como caso Frye), de 1923, onde se debatia a respeito da utilização em juízo de instrumento antecessor ao comumente chamado de "detector de mentiras" ou polígrafo. Utilizava-se, à época, análise das variações na pressão sanguínea para verificar as mudanças nas emoções e correlacioná-las com os diversos sentimentos de medo, raiva, dor, etc ${ }^{27}$.

A Suprema Corte Americana acabou por rejeitar a utilização do instrumento sob a alegação de que não havia suficiente referendo da comunidade científica no que tange à confiabilidade do detector de mentiras.

Trecho destacado da decisão é o seguinte:

Just when a scientific principle or discovery crosses the line between the experimental and demonstrable stages is difficult to define. Somewhere in this twilight zone the evidential force of the principle must be recognized, and while courts will go a long way in admitting expert testimony deduced from a well-recognized scientific principle or discovery, the thing from which the deduction is made must be sufficiently established to have gained general acceptance in the particular field in which it belongs. ${ }^{28}$

Daí, apesar da ausência de sistematização do critério, firmou-se o entendimento de que a prova científica somente seria admitida no processo judicial quando se verificasse uma general acceptance, ou aceitação geral, daquele método ou técnica entre o meio científico e acadêmico respectivo. Este filtro de aceitação geral acabou conhecido como Frye test. Não seria suficiente que peritos atestassem, no processo, a qualidade do método ou da técnica, pois esta declaração poderia ser distorcida em razão dos interesses da parte que patrocinava a atuação do perito. Assim, "Frye impôs um ônus especial: a técnica deve ser generalizadamente aceita pela comunidade científica relevante" ${ }^{29}$.

Atente-se que em virtude mesmo da natureza mutável e em constante desenvolvimento do pensamento científico, não se deveria exigir - se possível falar - uma certeza absoluta, mas sim que a maioria da comunidade científica aceitasse o método ou a técnica como os mais adequados a determinada situação ${ }^{30}$.

Todavia, ao mesmo tempo em que significava uma busca de segurança quanto ao método ou técnica, o Frye test acabava por excluir da análise em juízo as novas tecnologias muitas vezes mais eficazes que os antigos métodos tidos por consagrados ${ }^{31}$.

Em 1975, a Federal Rules of Evidence passou a tratar da produção das provas no processo norte-americano, inclusive as perícias. Assim, além da base jurisprudencial, passou também a haver base legal para o regramento das provas, o que muitas vezes levava a divergência na aplicação da regra jurisprudencial ou da regra legal.

\section{Caso Daubert vs. Merrell Dow Pharmaceuticals, Inc.}

O primeiro caso na jurisprudência norte-americana onde houve um esforço hermenêutico para a sistematização da prova técnica e científica é o caso Daubert vs. Merrell Dow Pharmaceuticals, Inc. (doravante chamada de Daubert), de 1993, onde se debatia a respeito do eventual nexo de causalidade entre o medicamento Bendectim ministrado a uma mulher grávida e o nascimento dos seus gêmeos com enfermidades congênitas.

27 CASTRO, Carla Rodrigues Araújo de. Prova Científica: Exame Pericial do DNA. Rio de Janeiro: Lumen Juris, 2007. pp. $120-121$.

28 FRYE v. UNITED STATES. 293 F. 1013 (D.C. Cir 1923). Disponível em < http://www.law.ufl.edu/pdf/faculty/ little/topic8.pdf> Acesso em 25/05/2020.

29 MANZANO, Luiz Fernando de Moraes. Prova Pericial... Ob. cit.. p.189.

30 CASTRO. Carla Rodrigues Araújo de. Prova Científica... Ob. cit. pp. 122-123.

31 MANZANO, Luiz Fernando de Moraes. Prova Pericial... Ob. cit.. p. 195. 
Enquanto a empresa trouxe ao processo diversos estudos científicos onde era demonstrado que o uso do Bendectim não provocava malformações em fetos, a autora trouxe oito peritos para depor a respeito de testes feitos em animais que demonstravam a correlação entre o princípio ativo do Bendectim e a malformação dos fetos. Esta última prova restou inadmitida.

A Suprema Corte dos Estados Unidos acabou por confrontar o Frye test às rules $401^{32}$ e 702 (em sua redação original) ${ }^{33}$, concluindo por dispensar a general acceptance para a admissibilidade da prova pericial, requisito àquela altura tido por restritivo ${ }^{34}$, vez que as Federal Rules os Evidence seriam incompatíveis com esta exigência, admitindo de forma mais ampla a atuação da expert witness. Em verdade, "A review of the caselaw after Daubert shows that the rejection of expert testimony is the exception rather than the rule" 35. Toda prova relevante seria admissível (rule 401), na medida em que a aceitação geral não era elemento necessário à admissibilidade conforme a rule $702^{36}$. Eis o trecho do julgamento: "Nothing in the text of this Rule establishes 'general acceptance' as an absolute prerequisite to admissibility. Nor does respondent present any clear indication that Rule 702 or the Rules as a whole were intended to incorporate a 'general acceptance' standard" $"$.

Aqui foram estabelecidos, pela primeira vez, critérios de seleção preliminar das provas científicas, visando exatamente excluir do processo a produção da junk science $e^{38}$. A fixação de critérios se deu com o escopo de uniformizar o exame de admissibilidade da expert evidence, pondo critérios na máxima medida objetivos ${ }^{39}$.

Ao fim, acabaram por prevalecer os seguintes filtros de análise prévia da prova especializada:

a) a verificabilidade ou testabilidade do método ou técnica. Ou seja, se há a possibilidade ou se houve o efetivo teste do método ou teoria aplicada. Conforme anotou a Corte:

Ordinarily, a key question to be answered in determining whether a theory or technique is scientific knowledge that will assist the trier of fact will be whether it can be (and has been) tested. "Scientific methodology today is based on generating hypotheses and testing them to see if they can be falsified; indeed, this methodology is what distinguishes science from other fields of human inquiry." Green 645. See also C. Hempel, Philosophy of Natural Science 49 (1966). ${ }^{40}$

A questão problemática aqui reside exatamente em saber se os magistrados têm condições de avaliar critérios nestes moldes, mormente porque eles mesmos exigiriam conhecimento especializado. ${ }^{41}$

32 Rule 401. Evidence is relevant if: (a) it has any tendency to make a fact more or less probable than it would be without the evidence; and (b) the fact is of consequence in determining the action.

33 Rule 702 (redação original): If scientific, technical, or other specialized knowledge will assist the trier of fact to understand the evidence or to determine a fact in issue, a witness qualified as an expert by knowledge, skill, experience, training, or education may testify thereto in the form of an opinion or otherwise.

34 Atenta Paula Bezerra de Menezes que "A aplicabilidade do teste Frye, considerado muito rígido, foi declarada incompatível com a flexibilidade implementada pela FRE. Deixou-se claro que a flexibilidade não implica admissão livre de qualquer tipo de prova pericial, mas somente daquela considerada relevante e confiável.” MENEZES, Paula Bezerra de. Novos rumos da prova pericial. Rio de Janeiro: 7Letras, 2014. p. 110.

35 Trecho da nota do Comitê de Emenda à Rule 702. Disponível em <https://www.law.cornell.edu/rules/fre/ rule 702> Acesso em 25/05/2020.

36 MANZANO, Luiz Fernando de Moraes. Prova Pericial... Ob. cit. p. 197.

37 DAUBERT, v. MERRELL DOW PHARMACEUTICALS, INC. 509 U.S. 579, 113 S.Ct. 2786) (1992). Disponível em <http://www.law.ufl.edu/pdf/faculty/little/topic8.pdf> Acesso em 25/05/2020. Continua: "The drafting history makes no mention of Frye, and a rigid "general acceptance" requirement would be at odds with the "liberal thrust" of the Federal Rules and their "general approach of relaxing the traditional barriers to 'opinion' testimony." Beech Aircraft Corp. v. Rainey, 488 U.S., at 169, 109 S.Ct., at 450 (citing Rules 701 to 705).

38 TARUFFO, Michele. A Prova. Ob. cit. p. 96.

39 MENEZES, Paula Bezerra de. Novos Rumos... Ob. cit. p. 107.

40 DAUBERT, v. MERRELL DOW PHARMACEUTICALS, INC. 509 U.S. 579, 113 S.Ct. 2786) (1992). Disponível em <http://www.law.ufl.edu/pdf/faculty/little/topic8.pdf> Acesso em 25/05/2020.

41 ALMEIDA, Diogo Assumpção Rezende de. A prova pericial... Ob. cit. pp. 25-28. 
Veja-se que o Comitê de emenda à Rule 702 afirma que o juiz deve verificar se o método ou técnica a ser utilizado pelo expert "is properly grounded, well-reasoned, and not speculative before it can be admitted" 2 .

Ora, para verificar se um método científico é fundamentado, razoável e não especulativo, não se exigiria do juiz também um conhecimento concernente àquela área do conhecimento que vá além do homemmédio?

b) a análise da taxa de erro conhecido ou potencial do método ou técnica. É função do perito a demonstração do percentual de erro nos testes aplicados em laboratório. Conforme anotou a Corte: "Additionally, in the case of a particular scientific technique, the court ordinarily should consider the known or potential rate of error, see, e.g., United States v. Smith, 869 F.2d 348, 353-354 (CA7 1989)"43.

Assume especial importância este critério quando há conflito de métodos ou técnicas, ou seja, quando ambas as partes trazem à baila perícias baseadas em métodos diversos.

Conforme atentou o Comitê de emenda à Rule 702, é possível que os peritos apliquem técnicas ou métodos diversos em um mesmo processo. Impõe-se, pois, demonstrar a sua respectiva confiabilidade:

As the court stated in In re Paoli R.R. Yard PCB Litigation, 35 F.3d 717, 744 (3d Cir. 1994), proponents "do not have to demonstrate to the judge by a preponderance of the evidence that the assessments of their experts are correct, they only have to demonstrate by a preponderance of evidence that their opinions are reliable. . . . The evidentiary requirement of reliability is lower than the merits standard of correctness" ${ }^{\prime 4}$.

No próprio caso Daubert, a Corte deixou claro que o foco, quando da admissibilidade da prova pericial, é verificar os princípios e a metodologia a serem utilizados, e não os resultados decorrentes de sua aplicação. Tal entendimento decorre, logicamente, de estarmos tratando da admissibilidade da prova e não de sua valoração.

É também este critério elemento fundamental para se compreender a razão de o juiz não estar vinculado ao resultado da perícia. Muitas vezes os métodos disponíveis apresentam elevado percentual de erro, devendo ser confrontados com todo o arcabouço probatório produzido nos autos.

c) o peer-review, com o objetivo de demonstrar a maturidade das pesquisas e análises a respeito daquele conhecimento a partir de publicações científicas sujeitas ao controle da comunidade acadêmica ${ }^{45}$. Exigese a publicação, a crítica e a revisão das teorias como requisitos para a sua confiabilidade ${ }^{46}$. Veja-se, nas palavras da Corte:

Another pertinent consideration is whether the theory or technique has been subjected to peer review and publication. Publication (which is but one element of peer review) is not a sine qua non of admissibility; it does not necessarily correlate with reliability, see S. Jasanoff, The Fifth Branch: Science Advisors as Policymakers 61-76 (1990), and in some instances well-grounded but innovative theories will not have been published, see Horrobin, The Philosophical Basis of Peer Review and the Suppression of Innovation, 263 JAMA 1438 (1990). Some propositions, moreover, are too particular, too new, or of too limited interest to be published. But submission

42 Trecho da nota do Comitê de Emenda à Rule 702. Disponível em <https://www.law.cornell.edu/rules/fre/ rule 702> Acesso em 25/05/2020.

43 DAUBERT, v. MERRELL DOW PHARMACEUTICALS, INC. 509 U.S. 579, 113 S.Ct. 2786) (1992). Disponível em <http://www.law.ufl.edu/pdf/faculty/little/topic8.pdf > Acesso em 25/05/2020.

44 Trecho da nota do Comitê de Emenda à Rule 702. Disponível em <https://www.law.cornell.edu/rules/fre/ rule 702> Acesso em 25/05/2020.

45 Paula Bezerra de Menezes é mais criteriosa da definição do peer review. Em verdade, “peer review" é o nome consagrado para este critério de admissibilidade da prova pericial, conquanto o termo em comento tenha outro significado daquele utilizado no caso Daubert. Explica a autora: "Peer review, ou como o nome diz revisão por pares, é o processo instituído no meio científico de revisão prévia à publicação de um artigo. $\mathrm{O}$ autor submete seu artigo a um editor, que o entrega, normalmente, a dois cientistas da área de mesmo nível intelectual ou superior ao do autor. Os revisores têm a função de analisar criticamente a hipótese e aprová-la, ou não, quando as críticas serão enviadas ao autor para aprimoramento de pesquisa ou para a retificação de dados, por exemplo.” MENEZES, Paula Bezerra de. Novos Rumos... Ob. cit. p. 119.

46 MANZANO, Luiz Fernando de Moraes. Prova Pericial... Ob. cit. p. 202. 
to the scrutiny of the scientific community is a component of "good science," in part because it increases the likelihood that substantive flaws in methodology will be detected. ${ }^{47}$

A ideia aqui é submeter o método ou a técnica a ser utilizada a um julgamento dos próprios pares estudiosos do mesmo ramo do conhecimento especializado. Trata-se de verificar a credibilidade do conhecimento.

O problema é que alguns estudos podem ser muito recentes ou específicos, de forma que não se encontre ampla gama de revisões a respeito. Esta ausência, por si só, não estaria apta a desconstruir a qualidade do conhecimento aportado.

d) o consenso ou aceitação do método perante a comunidade científica, devendo-se manter os padrões de qualidade metodológicos e técnicos.

Ao fim, apesar de supostamente superar o Frye test, a Suprema Corte em Daubert também mencionou a necessidade de aceitação da comunidade científica (mantendo-a como mais um critério e não como único critério) e, ainda, que o método e a técnica não tivessem sido desenvolvidos para uso exclusivo na instrução processual. Nos termos originais:

Finally, "general acceptance" can yet have a bearing on the inquiry. (...) Widespread acceptance can be an important factor in ruling particular evidence admissible, and "a known technique which has been able to attract only minimal support within the community," Downing, 753 F.2d, at 1238, may properly be viewed with skepticism. ${ }^{48}$

O problema que restou foi o seguinte: ao mesmo tempo em que a Suprema Corte Americana afirmou que o Frye test (=exame de general acceptance) significava uma maior rigidez e por isso deveria ser superado pela Federal Rules of Evidence interpretada a partir de Daubert, acabou por impor não somente um, mas quatro critérios de admissibilidade da prova técnica e científica. Não obstante a pretensão de tornar mais flexível a utilização deste meio de prova ${ }^{49}$, acabou por promover o efeito contrário, tornando mais dificultoso o aporte de conhecimento técnico e científico ao processo ${ }^{50}$.

Enfim, o problema dos critérios de admissibilidade da expert evidence não foi resolvido.

\section{Caso Kumho Tire Co. vs. Carmichael}

Por fim, a Suprema Corte se deparou com o caso Kumho Tire Co. vs. Carmichael (conhecido como caso Kumho, de 1999), onde se discutiu a respeito do nexo causal entre um acidente de carro e o suposto defeito nos pneus do veículo. O debate sobre a expert evidence se deu em verificar a necessidade ou não de respeito cumulativo a todos os critérios para a admissibilidade da prova.

A Suprema Corte acabou por relativizar os requisitos firmados no caso Daubert, afirmando que a sua aplicação cumulativa ou alternativa depende do ramo do conhecimento especializado. Veja-se, ipsis literis:

We also conclude that a trial court may consider one or more of the more specific factors that Daubert mentioned when doing so will help determine that testimony's reliability. But, as the Court stated in Daubert, the test of reliability is "flexible," and Daubert's list of specific factors neither necessarily nor exclusively applies to all experts or in every case ${ }^{51}$.

47 DAUBERT, v. MERRELL DOW PHARMACEUTICALS, INC. 509 U.S. 579, 113 S.Ct. 2786) (1992). Disponível em <http://www.law.ufl.edu/pdf/faculty/little/topic8.pdf > Acesso em 25/05/2020.

48 DAUBERT, v. MERRELL DOW PHARMACEUTICALS, INC. 509 U.S. 579, 113 S.Ct. 2786) (1992). Disponível em <http://www.law.ufl.edu/_pdf/faculty/little/topic8.pdf> Acesso em 25/05/2020.

49 MANZANO, Luiz Fernando de Moraes. Prova Pericial... Ob. cit. p. 199.

50 Na mesma linha de raciocínio: ALMEIDA, Diogo Assumpção Rezende de. A prova pericial... Ob. cit. pp. $22-25$.

51 KUM HO TIRE COM PANY, LTD., v. CARMICHAEL 526 U.S. 137, 119 S.Ct. 1167) ( 1999). Disponível em < $\underline{\text { http: } / /}$ www.law.ufl.edu/_pdf/faculty/little/topic8.pdf>. Acesso em 25/05/2020. 
As circunstâncias concretas po.dem justificar a inaplicabilidade e consequente dispensa de um ou outro dos filtros instituídos no caso Daubert. Não é possível, por isso, estabelecer um critério prévio e geral para a admissibilidade da prova técnica ou científica. Ainda nas palavras da Suprema Corte:

The conclusion, in our view, is that we can neither rule out, nor rule in, for all cases and for all time the applicability of the factors mentioned in Daubert, nor can we now do so for subsets of cases categorized by category of expert or by kind of evidence. Too much depends upon the particular circumstances of the particular case at issue ${ }^{52}$.

Apesar disso, impõe-se um juízo de confiabilidade do método ou técnica utilizado, além de um juízo de relevância da prova para o processo ${ }^{53}$. O problema, como se pode perceber, é a ausência de critérios sólidos para este juízo, mormente após as conclusões da Suprema Corte em Kumho.

A Federal Rules of Evidence foi reformada no ano de 2000 para adequar seus dispositivos ao decidido nos casos Daubert e Kumho, especificando fatores para o controle de admissibilidade do conhecimento especializado no processo $^{54}$. Segundo anotou o Comitê de reforma à Rule 702:

\begin{abstract}
Daubert set forth a non-exclusive checklist for trial courts to use in assessing the reliability of scientific expert testimony. The specific factors explicated by the Daubert Court are (1) whether the expert's technique or theory can be or has been tested-that is, whether the expert's theory can be challenged in some objective sense, or whether it is instead simply a subjective, conclusory approach that cannot reasonably be assessed for reliability; (2) whether the technique or theory has been subject to peer review and publication; (3) the known or potential rate of error of the technique or theory when applied; (4) the existence and maintenance of standards and controls; and (5) whether the technique or theory has been generally accepted in the scientific community. The Court in Kumho held that these factors might also be applicable in assessing the reliability of nonscientific expert testimony, depending upon "the particular circumstances of the particular case at issue." 119 S.Ct. at 1175.5
\end{abstract}

Esta reforma, todavia, não foi apta a resolver o problema dos critérios a serem aplicados para a admissibilidade do aporte de conhecimentos especializados no processo. O próprio Comitê de reforma, ao longo da supracitada nota, afirma que os critérios não são exclusivos ou necessários. Inclusive, menciona tantos outros elementos citados em obiter dicta que podem servir como relevantes instrumentos de controle de admissibilidade da prova $^{56}$.

\title{
7. Conclusão
}

52 KUM HO TIRE COM PANY, LTD., v. CARMICHAEL 526 U.S. 137, 119 S.Ct. 1167) ( 1999). Disponível em < $\underline{\text { http: } / \not}$ www.law.ufl.edu/pdf/faculty/little/topic8.pdf> Acesso em 25/05/2020. E continua: "Daubert itself is not to the contrary. It made clear that its list of factors was meant to be helpful, not definitive."

$53 \quad$ "In Daubert, this Court held that Federal Rule of Evidence 702 imposes a special obligation upon a trial judge to "ensure that any and all scientific testimony ... is not only relevant, but reliable.” 509 U.S., at 589, 113 S.Ct. $2786 . "$ KUM HO TIRE COM PANY, LTD., v. CARMICHAEL 526 U.S. 137, 119 S.Ct. 1167) ( 1999). Disponível em < http: //www.law.ufl.edu $/$ pdf/faculty/little/topic8.pdf> Acesso em 25/05/2020.

54 Rule 702. Testimony by Expert Witnesses. A witness who is qualified as an expert by knowledge, skill, experience, training, or education may testify in the form of an opinion or otherwise if: (a) the expert's scientific, technical, or other specialized knowledge will help the trier of fact to understand the evidence or to determine a fact in issue; (b) the testimony is based on sufficient facts or data; (c) the testimony is the product of reliable principles and methods; and (d) the expert has reliably applied the principles and methods to the facts of the case.

Houve ainda uma emenda em 2011. Contudo, conforme a nota do próprio Comitê à Emenda: "The language of Rule 702 has been amended as part of the restyling of the Evidence Rules to make them more easily understood and to make style and terminology consistent throughout the rules. These changes are intended to be stylistic only. There is no intent to change any result in any ruling on evidence admissibility." Disponível em < https://www.law.cornell.edu/rules/fre/rule $702>$ Acesso em 25/05/2020.

55 Trecho da nota do Comitê de Emenda à Rule 702. Disponível em < $\underline{\text { https: } / / \text { www.law.cornell.edu/rules/fre/ }}$ rule 702> Acesso em 25/05/2020.

56 Listar um por um e explicar cada um destes fatores foge aos limites deste trabalho. Indica-se a leitura da nota, conforme citado acima. 
Apesar de todas as tentativas, é infindável o debate acerca da busca de métodos objetivamente capazes de definir a necessidade ou relevância de uma prova pericial. Em verdade, a pretensão de construção destes critérios de forma definitiva parece utópica.

Esta constatação, todavia, não dispensa ou torna inúteis os critérios construídos. Pelo contrário, nos oferece elementos de avaliação e fundamentação das decisões que admitem ou negam a produção da prova. Nesse sentido, a presença de requisitos cada vez mais claros e o reforço do processo cooperativo visam reduzir este espaço de indefinição e de incomunicabilidade entre o processo e o ramo da ciência que deva aportar.

A observação dos critérios apresentados neste excerto reduz o espectro de indefinição. Ainda que não seja possível exigir sua presença cumulativa em todos os casos, podem servir como balizas para o juízo de necessidade da prova pericial em nosso Direito: i) se o método utilizado já foi objeto de falseamento, tendo obtido sucesso na explicação dos fenômenos com os quais confrontado; ii) se há revisão doutrinária a respeito dele, cuja aceitação é majoritária na área específica do conhecimento; iii) se há conhecimento dos percentuais de erro e das formas de controlar as distorções na aplicação daquele método, a serem confrontados com os standars probatórios para o caso concreto, justificando ou não sua utilização; iv) se o método possui a aceitação geral no âmbito da comunidade científica.

O CPC, nesse sentido, explicitamente consagra a necessidade de se observar o último dos requisitos apontados: a general aceptance. É como se lê do art. 473, III: "O laudo pericial deverá conter: (...) III - a indicação do método utilizado, esclarecendo-o e demonstrando ser predominantemente aceito pelos especialistas da área do conhecimento da qual se originou; (...)”.

Todavia, o dispositivo supramencionado cuida dos requisitos do laudo pericial, ou seja, da necessidade de o expert justificar a utilização do método após a realização do exame pericial. O que defendemos, aqui, é que tais critérios precisam ser observados em momento anterior, qual seja, o da admissibilidade da prova ${ }^{57}$.

Por isso, imprescindível a análise da jurisprudência norte-americana. Se houve um desenvolvimento da matéria antes lá do que cá, podemos aproveitar os aspectos exitosos de tal experiência, especialmente para recepcionar e utilizar em nossa realidade critérios mais seguros para fundamentar as decisões judiciais e promover a realização das provas técnicas e científicas no Brasil.

\section{REFERÊNCIAS}

ALMEIDA, Diogo de Assumpção Rezende. A prova pericial no processo civil: o controle da ciência e a escolha do perito. Rio de Janeiro: Renovar, 2011.

AVELINO, Murilo Teixeira. O controle judicial da prova técnica e científica. Salvador: JusPodivm, 2017.

CARVALHO, Nathália Gonçalvez de Macedo. Introdução ao federal rules of evidence e os pontos de encontro com o Código de Processo Civil 2015. JOBIM, Marco Félix; FERREIRA, William Santos (coords). Direito Probatório. Salvador: JusPodivm, 2015.

CASTRO, Carla Rodrigues Araújo de. Prova Científica: Exame Pericial do DNA. Rio de Janeiro: Lumen Juris, 2007.

CINTRA, Antonio Carlos de Araujo. Comentários ao Código de Processo Civil - vol. IV. Rio de Janeiro: Forense, 2000.

CUNHA, Leonardo. A Atendibilidade dos Fatos Supervenientes no Processo Civil. Coimbra: Almedina, 2012.

CUNHA, Leonardo Carneiro da. A previsão do princípio da eficiência no projeto do novo código de processo civil brasileiro. Repro, São Paulo: RT, v. 233, 2014.

57 AVELINO, Murilo Teixeira. O controle judicial da prova técnica e científica. Salvador: JusPodivm, 2017. p. 173. 
MANZANO, Luíz Fernando de Moraes. Prova Pericial: Admissibilidade e assunção da prova científica e técnica no processo brasileiro. São Paulo: Atlas, 2011.

MARINONI, Luiz Guilherme; MITIDIERO, Daniel. Código de processo civil comentado artigo por artigo $2^{\underline{a}}$ ed. São Paulo: RT, 2010.

MARINONI, Luiz Guilherme; ARENHART, Sérgio Cruz. Prova e Convição. São Paulo: RT, 2015.

MENEZES, Paula Bezerra de. Novos rumos da prova pericial. Rio de Janeiro: 7Letras, 2014.

MIRANDA, Pontes de. Comentários ao Código de Processo Civil - tomo IV. Rio de Janeiro: Forense, 1974.

NERY JUNIOR, Nelson. Princípios do Processo na Constituição Federal. São Paulo: RT, 2013.

PEÑA, Eduardo Chemale Selistre. Poderes e atribuições do juiz. São Paulo: Saraiva, 2014.

SANTOS, Moacyr Amaral. Prova Judiciária no Cível e Comercial - vol. 1. São Paulo: Max Limonad, 1954.

SPENCER, A. Benjamin. Civil Procedure - A Contemporary Approach. St. Paul, MN: Thomson/West, 2007.

TARUFFO, Michele. Uma simples verdade. O juiz e a construção dos fatos. Madri: Marcial Pons, 2012.

TARUFFO, Michele. A prova. São Paulo: Marcial Pons, 2014.

YEAZELL, Stephen C. Civil Procedure. New York, NY: Aspen Publishers, 2008. 